\title{
Redox and Thiols in Archaea
}

\author{
Mamta Rawat ${ }^{1, *}$ and Julie A. Maupin-Furlow ${ }^{2,3, *(\mathbb{D})}$ \\ 1 Biology Department, California State University, Fresno, CA 93740, USA \\ 2 Department of Microbiology and Cell Science, Institute of Food and Agricultural Sciences, \\ University of Florida, Gainesville, FL 32611, USA \\ 3 Genetics Institute, University of Florida, Gainesville, FL 32611, USA \\ * Correspondence: mrawat@csufresno.edu (M.R.); jmaupin@ufl.edu (J.A.M.-F.)
}

Received: 31 March 2020; Accepted: 2 May 2020; Published: 5 May 2020

check for updates

\begin{abstract}
Low molecular weight (LMW) thiols have many functions in bacteria and eukarya, ranging from redox homeostasis to acting as cofactors in numerous reactions, including detoxification of xenobiotic compounds. The LMW thiol, glutathione (GSH), is found in eukaryotes and many species of bacteria. Analogues of GSH include the structurally different LMW thiols: bacillithiol, mycothiol, ergothioneine, and coenzyme A. Many advances have been made in understanding the diverse and multiple functions of GSH and GSH analogues in bacteria but much less is known about distribution and functions of GSH and its analogues in archaea, which constitute the third domain of life, occupying many niches, including those in extreme environments. Archaea are able to use many energy sources and have many unique metabolic reactions and as a result are major contributors to geochemical cycles. As LMW thiols are major players in cells, this review explores the distribution of thiols and their biochemistry in archaea.
\end{abstract}

Keywords: archaea; low molecular weight thiols; glutathione; $\gamma$-glutamylcysteine; coenzyme A; redox cycling

\section{Introduction}

Low molecular weight (LMW) thiols, a group of highly reactive compounds containing a sulfhydryl $(-\mathrm{SH})$ functional group, play critical roles within a cell [1]. Thiols can: (i) serve as a storage form for cysteine, which can rapidly auto-oxidize in the presence of metals especially copper and iron [2,3], (ii) directly donate electrons to oxidants becoming oxidized in the process, forming disulfides (RS-SR) [4,5], (iii) conjugate xenobiotic agents making them more soluble [6], (iv) form complexes with metal ions [7], and (v) act as cofactors to different enzymes, such as ribonucleotide reductases [8] and methionine sulfoxide reductases [9]. Because of these roles, LMW thiols are considered ubiquitous among living organisms.

Glutathione (GSH) is a tripeptide of $\gamma$-L-glutamyl-L-cysteinylglycine that represents the major LMW thiol among eukaryotes, whereas prokaryotes more commonly synthesize alternative LMW thiols even if GSH is present [1]. Ergothioneine (EGT) [10-12], trypanathione, bis-glutathione [13], glutathione amide [14], $\gamma$-glutamylcysteine $(\gamma \mathrm{GC})$, mycothiol (MSH) $[15,16]$, coenzyme A (CoA), and bacilithiol (BSH) are some of the other LMW thiols (Figure 1). Interestingly, even in bacteria that contain GSH, this LMW thiol can be acquired by pathways that differ from the canonical pathway in which GSH is synthesized by the two ligases, $\gamma$-glutamate-cysteine ligase $(\gamma$-ECL) and glutathione synthetase (GS). These alternative pathways of GSH acquisition include import [17,18] and the use of a novel fusion protein, GshF, for the biosynthesis of GSH in bacteria that were once thought to lack GSH [19]. The diversity in structure of LMW thiols is now being appreciated and their functions are slowly being unraveled. 


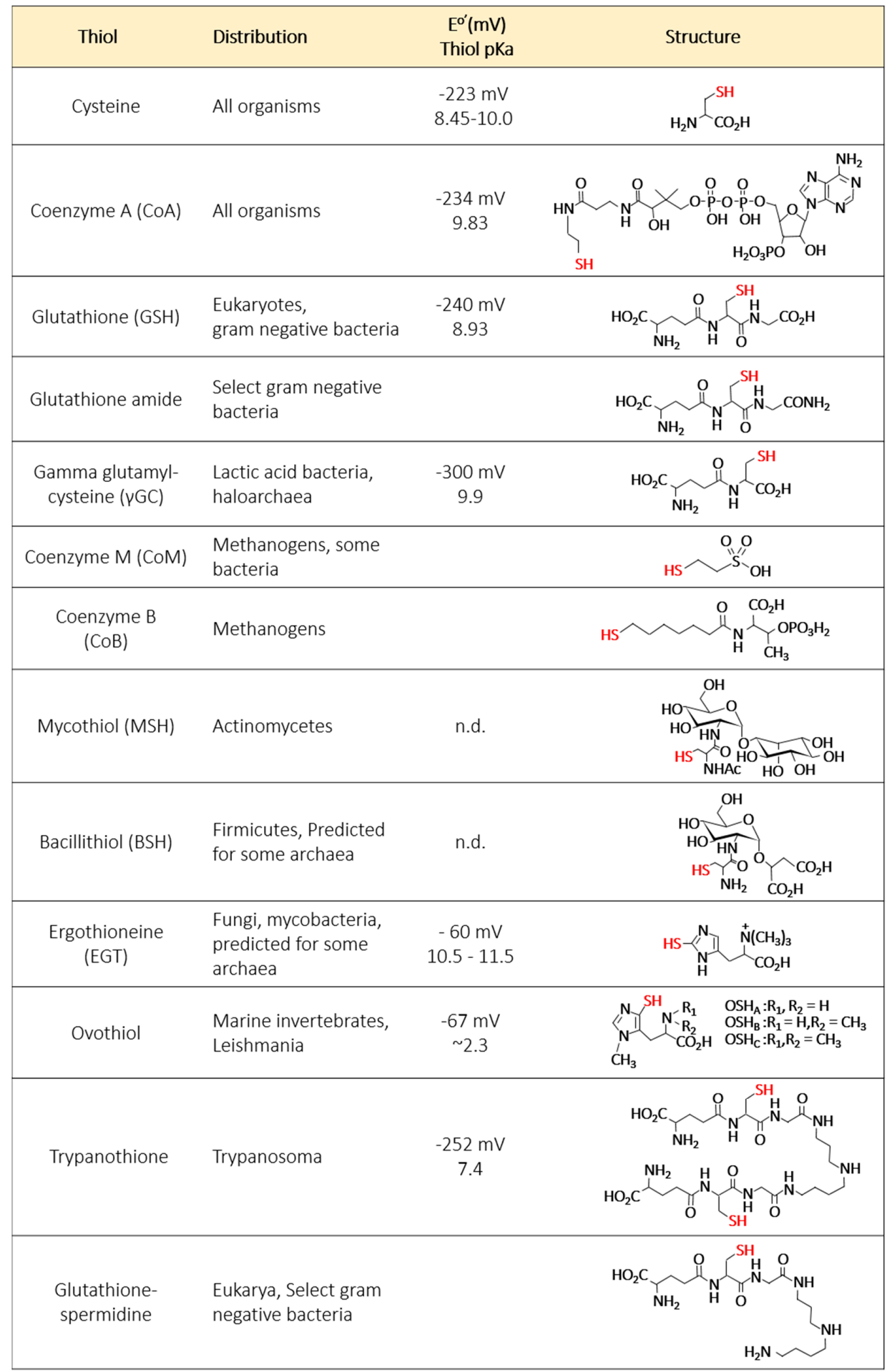

Figure 1. The chemistry of low molecular weight (LMW) thiols and their distribution among phylogenetic groups.

In recent years, much progress has been made in elucidating the structure and role of alternative LMW thiols in bacteria. $S$-thiolation of proteins in organisms containing alternative LMW thiols has been demonstrated [20]. However, the distribution, structure, and function of LMW thiols in archaea is still not apparent. This review paper will provide an overview of LMW thiols in prokaryotes with emphasis on the current state of knowledge regarding the distribution and biochemistry of these thiols in archaea. 


\section{Glutathione and $\gamma$-Glutamylcysteine}

Life on earth started in a reducing environment but the introduction of oxygen demanded an antioxidant network to cope with the oxidizing conditions. The dogma in the field has been that the antioxidant network consisted of GSH, as this LMW thiol is common in eukaryotes [21] and Gram-negative bacteria [16,22]. Thus, much attention has been devoted to finding this LMW thiol in archaea. The majority of bacterial and archaeal phyla have anaerobic basal members with aerobic members found only in derived positions. However, even in these anaerobic members, antioxidant networks are needed (e.g., Bacteriodes) and may have co-evolved as the oxygen levels rose [23].

GSH is synthesized in two sequential enzymatic steps [24]. The $g s h A$-encoded $\gamma \mathrm{GC}$ synthetase or ligase (GshA, EC 6.3.2.2; $\gamma$-ECL) ligates the amino group of cysteine to the $\gamma$-carboxyl group of glutamate. In turn, the gshB-encoded glutathione synthetase (GshB, EC 6.3.2.3; GS) condenses the resulting $\gamma \mathrm{GC}$ with glycine to generate GSH. A bifunctional GshF (GshAB) also exists that catalyzes both steps of GSH synthesis; the encoding gene appears to have spread by horizontal transfer in bacterial symbionts or pathogens, since most of the bacteria containing gshF gene homologs are found in domestic animals or humans [25]. Modifications of GSH exist as exemplified by the glutathione amide present in the purple green Chromatium [14,26], and ovothiol [27], and trypanothione [28] found mainly in unicellular eukaryotic parasites.

The first comprehensive report of a LMW thiol and its function in archaea was of $\gamma$ GC in the halophilic archaeon (haloarchaeon) Halobacterium salinarum (Halobacterium halobium R1) by Newton and Javor in 1985 [29]. Other haloarchaea (i.e., Haloarcula californiae, Haloarcula (Halobacterium) marismortui, Halobacterium saccharovorum, Haloferax (Halobacterium) volcanii, and Halococcus sp. LS-1) were also found to contain $\gamma \mathrm{GC}$ [29]. Haloarchaea live in high salt environments, greater than $3 \mathrm{M} \mathrm{NaCl}$, and possess cytoplasms with ionic strengths similar or exceeding those of their environment [30]. Sundquist and Fahey (1989) [31] demonstrated that the auto-oxidation of $\gamma \mathrm{GC}$ in the presence of copper was substantially lower in high salt buffer than low salt buffer and that $\gamma \mathrm{GC}$ was more stable in the high salt buffer than GSH was in the low salt buffer. Further analysis revealed the cytosolic concentration of $\gamma \mathrm{GC}$ was $4 \mathrm{mM}, 50$ fold higher than the oxidized $\gamma \mathrm{GC}$ (i.e., bis- $\gamma \mathrm{GC}$ ) in haloarchaea such as H. salinarum (halobium) [31]. While the gene was not identified in this early work, Sundquist and Fahey provided evidence in $H$. salinarum for a $\gamma \mathrm{GC}$ reductase (GCR) that was distinct from dihydrolipoamide dehydrogenase (DHD), the E3 component that oxidizes the thiol groups of dihydrolipoamide (Lip-(SH) 2 ) to lipoamide (Lip-(S) $\left.{ }_{2}\right)$ in $\alpha$-keto acid dehydrogenase complexes [31,32]. Kim and Copley (2013) [33] further expressed an H. salinarum (sp. NRC-1) gene annotated as mercuric reductase (MerA) in Escherichia coli and demonstrated that the enzyme had robust NADPH-dependent GCR activity but no mercuric reductase activity [33]. The genomes of most, but not all, haloarchaea for which whole genome sequences are available have homologues that are at least 50\% identical to GCR (UniRef 50 of UniProt Q9HSN0). These homologs, while uncharacterized, are often annotated as DHDs. However, haloarchaea use ferredoxin-dependent oxidoreductases to oxidize $\alpha$-keto acids such as pyruvate and $\alpha$-ketoglutarate, and, thus, these E3 homologs may not be needed for central metabolism $[34,35]$ and instead may code for GCRs. Malki et al. (2009) [36] further showed that H. volcanii gshA (HVO_1668) is able to synthesize $\gamma \mathrm{GC}$ in vivo. This haloarchaeal $g s h A$ gene can also restore synthesis of GSH in an E. coli gshA mutant despite only $15 \%$ sequence identity [36]. The phylogenetic analysis of the H. volcanii GshA demonstrated that it clusters with at least 10 other haloarchaeal GshA homologs at 64-75\% identity [36]. Thus, GshA and GCR are likely used to synthesize $\gamma$ GC and reduce the oxidized form of this LMW thiol in haloarchaea, respectively.

Genome mining suggests that, in addition to haloarchaea, other archaea may synthesize $\gamma \mathrm{GC}$ and/or GSH. In the early survey of LMW thiols in archaea, Newton and Javor (1985) reported that Sulfolobus acidocaldarius and five unidentified methanogens did not contain GSH or $\gamma$ GC [29]. However, a putative GshA (Msp_0528) from the methanogen Methanosphaera stadtmanae, was identified to form a distinct cluster that was related to haloarchaeal GshA, standalone $\gamma$-ECLs, and the N-terminal $\gamma$-ECL domain of bifunctional GshFs [36]. This GshA homolog is conserved in other Methanosphaera 
species and has over $50 \%$ sequence identity to homologs of Methanobrevibacter species including Methanobrevibacter ruminantium M1, which is responsible for the ruminant methane in ruminants worldwide [37]. While these latter ORFs are sometimes annotated as bifunctional GshFs, only the N-terminal $\gamma$-ECL domain is conserved suggesting $\gamma$ GC ligase, but not GS activity.

The InterPro database has two family classifications for GshA homologs, IPR006334 and IPR006336, which account for 676 total hits in archaea (Figure 2; Supplemental Table S1). Phylogenetic analysis by Copley and Dhillon (2002) indicates that GshA sequences fall into three groups including those primarily from: (i) $\gamma$-proteobacteria, (ii) non-plant eukaryotes, and (iii) $\alpha$-proteobacteria and plants, with the latter including sequences from haloarchaea [38]. From this early analysis, $\gamma$-ECL genes were suggested to have originated in cyanobacteria then to have undergone horizontal gene transfer (HGT) to other bacteria, eukaryotes, and at least some archaea [38]. Of the archaeal hits to the GshA InterPro families, most (496/676;73\%) are classified to the haloarchaea (Halobacteria class). The other hits are dispersed among other Euryarchaeota (methanogens, Archaeoglobi, and Thermoplasmata) and representatives of the Asgard, DPANN and TACK superphyla (Figure 2). While no archaeal hits for GshB (IPR037013) or GshF (GshAB) (IPR006335) are apparent, some $\mathrm{H}_{2}$-oxidizing methanogens (Methanobacterium sp.) have standalone GshB-like proteins related to the C-terminal ATP-grasp-like domain (IPR040657) of the GshAB fusion GshF. In genome synteny with these GshB-like ORFs are genes encoding GshA-like proteins related to the N-terminal domain of GshF (GshAB) suggesting certain methanogens may synthesize GSH.

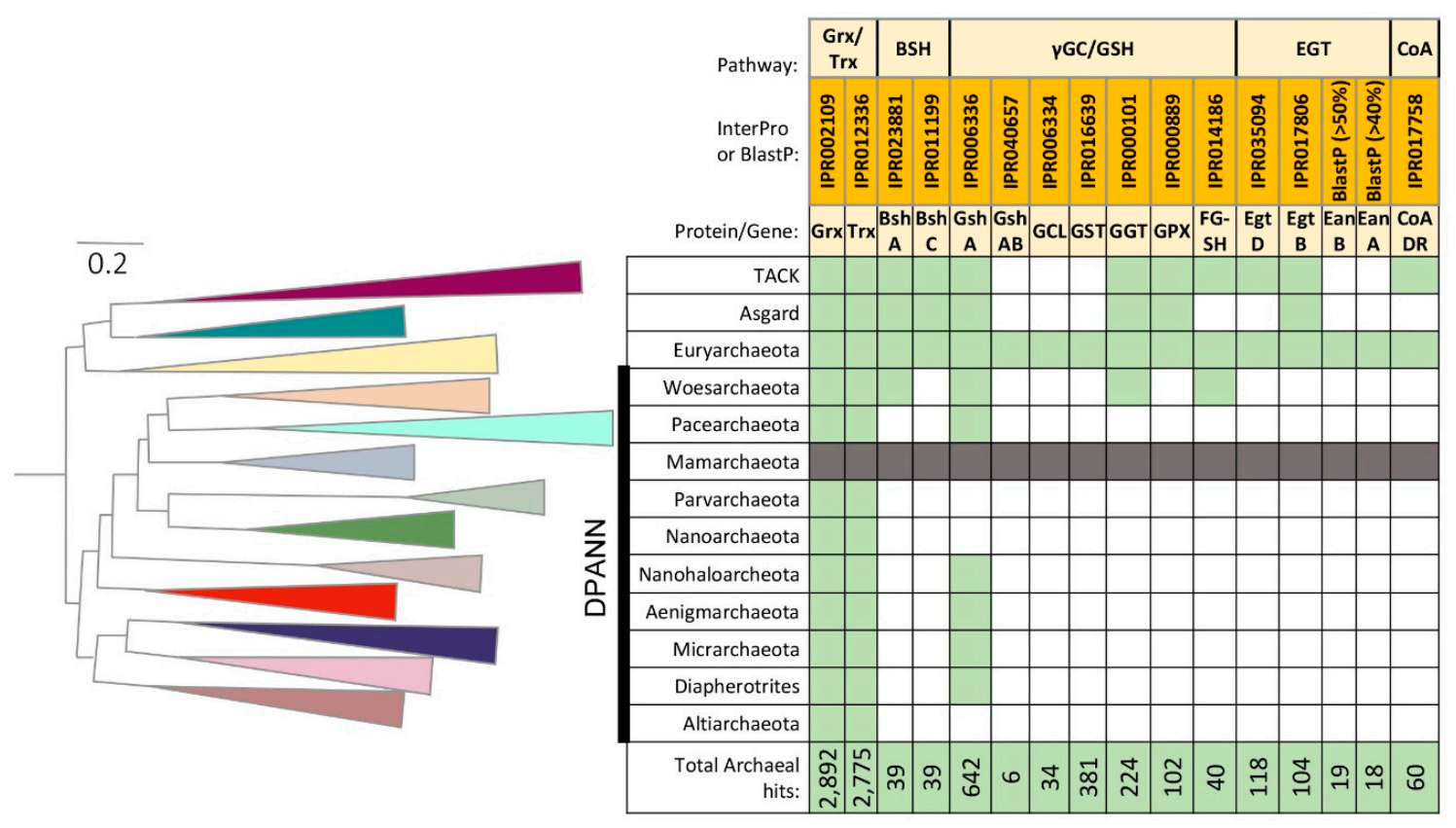

Figure 2. Archaeal protein homologs associated with thiol chemistry and their phylogenetic distribution. Left: Phylogenetic relationship of archaea based on Castelle et al. [39]. Phyla that cluster to DPANN indicated by black vertical bar. Right: Classification of archaeal homologs based on InterPro families and BlastP (See Supplemental Table S1 for details). Green boxes, archaeal groups with homologs. Grey boxes, Mamarchaeota genome unavailable for analysis.

\section{Protein Disulfide Relay Systems}

Small protein-based dithiols can serve directly or indirectly in disulfide relays as reductants for enzymatic reactions as well as for the repair or regulation of proteins that undergo oxidation [40]. Examples include the reduction of disulfide bonds created on enzymes as part of the formation of deoxyribonucleotides for DNA synthesis by reducing ribonucleotide reductase [8], the generation of reduced sulfur via 3'-phosphoadenylylsulfate [41], the reduction of methionine sulfoxide (an oxidized 
form of methionine) in the repair or regulation of oxidized proteins [9], the detoxification of $\mathrm{H}_{2} \mathrm{O}_{2}$ [42] and other activities of the cell. Most notable among the protein-based dithiol reductants are the thioredoxins (TRXs) and glutaredoxins (GRXs) that use active site cysteine residues in a CXXC motif. These cysteine residues are oxidized to form a disulfide bond upon transfer of the reductant to the substrate or enzyme and require regeneration by reduction for future reactions to proceed (Figure 3) $[43,44]$. For GRXs, the disulfide bond formed in the active site after reductant transfer can be reduced by LMW thiols, which in turn are oxidized. For example two GSHs can reduce the GRX disulfide resulting in GSH oxidation to GSSG, which is reduced by GSH reductase (EC 1.8.1.7), using reducing equivalents from NADPH [45]. By contrast to GRXs, TRXs are reduced enzymatically by TRX reductases which can be classified by active site and electron donor. Included in this classification are the: (i) NTRs, NAD(P)H-dependent TRX reductase flavoproteins (contain FAD coenzyme; EC 1.8.1.9) [46], with some also able to use hydrogen $\left(\mathrm{H}_{2}\right)$ [47], (ii) DFTRs, deazaflavin $\left(\mathrm{F}_{420}\right)$-dependent TRX reductase flavoproteins [48], (iii) FFTRs, ferredoxin (Fd)-dependent TRX reductase flavoproteins of certain bacteria [49], and iv) FTRs/FDRs, Fd: TRX reductases and Fd: disulfide reductases that use an active-site [4Fe-4S] cluster [50] (Figure 3). The $\mathrm{F}_{420}$ cofactor used by the DFTRs is distinct from FAD and is common to methanogenic archaea (Figure 4).

Thiol transferase systems that use protein dithiol reductants and TRX reductases are reported in archaea, with some of the archaeal TRXs characterized so far having TRX activity but an apparent GRX-like structure. NTRs that bind FAD and reduce TRXs using NAD(P)H are observed in the hyperthermophilic crenarchaeota Saccharolobus (Sulfolobus) solfataricus [51,52] and Aeropyrum pernix K1 [53]. NTRs are also reported in hyperthermophilic euryarchaeota, such as Pyrococcus horikoshii [54] and Thermococcus onnurineus, with the latter incorporating a TRX reductase that can also directly use $\mathrm{H}_{2}$ as reductant [47]. A GRX-like protein from P. horikoshii has demonstrated TRX activity but no GRX activity, meaning that it requires a TRX reductase for reactivation [54]. Likewise, a GRX-like protein disulfide oxidoreductase (PDO), is described in S. solfataricus to accept reductant from NTR and transfer this to enzymatic reactions in the cell $[52,55]$. Most methanogens have multiple TRX homologues with distinct functions [56]. One exception is Methanopyrus kandleri of the order Methanopyrales, which has a complete genome sequence and no predicted TRX homolog [57]. Constant with this TRX distribution in methanogens, NTR and FDR enzymes are observed in Methanosarcina acetivorans $[50,56]$. Likewise, an FFTR was identified in the hyperthermophilic methanogen Methanocaldococcus jannaschii, that can reduce TRXs [48] as well as a protein similar in structure to GRX that acts like a TRX [58]. Methanobacterium thermoautotrophicum, a methanogen that grows optimally at $\sim 65{ }^{\circ} \mathrm{C}$, contains a GRX-like protein [59]. GSH, TRX or the two thiols identified in extracts of $M$. thermoautotrophicum, hydrogen sulfide and 2-mercaptoethanesulfonate (coenzyme $\mathrm{M}, \mathrm{CoM}$ ), were not able to serve as reductants but dihydrolipoate could in a GRX-like activity assay that monitored the reduction of insulin disulfide [59]. In addition, a GRX-like protein in M. acetivorans, was named methanoredoxin (MRX) [60] because it used CoM-SH as reductant in the insulin disulfide reductase assay. CoM along with coenzyme B (CoB) are thiol-based coenzymes that form a heterodisulfide (CoM-S-S-CoB) during methanogenesis [61]. Consistent with the possibility that CoM-SH could serve as a GRX-like reductant, a CoM disulfide reductase is described in M. thermoautotrophicum that regenerates CoM-S-S-CoM to CoM-SH [62]. In $\gamma$ GC containing haloarchaea, thioltransferase activity is observed and suggested to be used to reduce disulfides which are part of an enzymatic cycle [63]; alternatively, in the absence of a LMW thiol, TRX could perform the functions attributed to the GRX-like activity [64]. InterPro search for GRX-like homologs in archaea yielded 2892 hits, while the TRX-like fold yielded another 2775 hits (Table S1) with many of these proteins having the conserved CXXC motif suggesting thiol-disulfide oxidoreductase activity is common in archaea. 


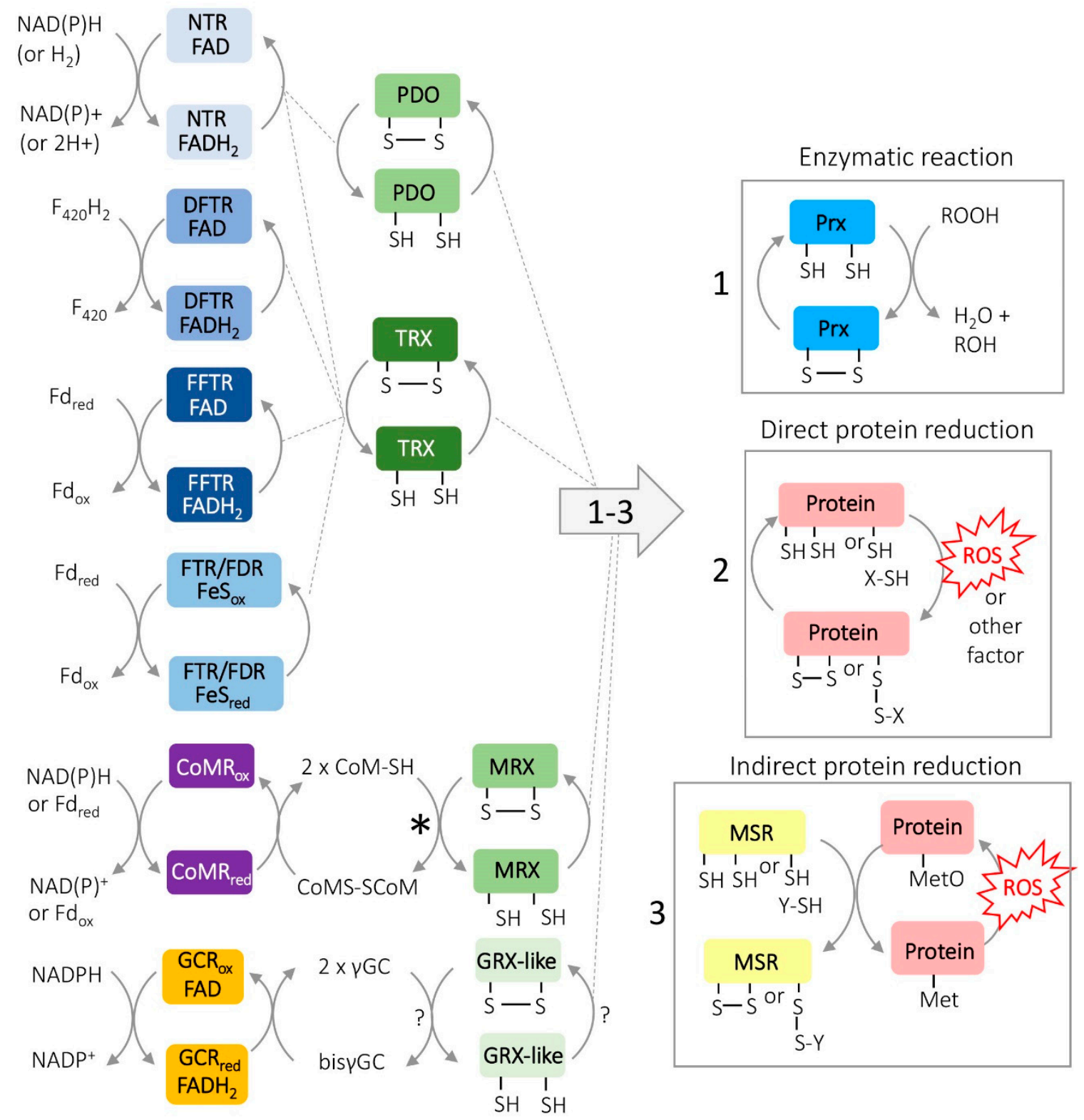

Figure 3. Protein disulfide relay systems. TRX, thioredoxin; GRX-like, glutaredoxin-like; MRX, methanoredoxin (GRX-like); and PDO, protein disulfide oxidoreducatase (GRX-like); NTR, NADPH-dependent TRX reductase; DFTR, deazaflavin $\left(\mathrm{F}_{420}\right)$-dependent flavin containing TRX reductase; FFTR, ferredoxin-dependent flavin TRX reductase; FTR, ferredoxin: TRX reductase that uses an active site [4Fe-4S] cluster; FDR, ferredoxin: disulfide reductase enzymes that uses an active-site [4Fe-4S] cluster; CoMR, coenzyme M disulfide reductase; CoM-SH and CoM-S-S-CoM, reduced and oxidized forms of coenzyme M; GCR, bis $\gamma \mathrm{GC}$ reductase; *, non-enzymatic reduction, ?, not demonstrated. Routes for protein thiol reductant (which may be general or specific): (1) catalytic reactions such as catalyzed by Prx, thiol-dependent preoxiredoxins; (2) direct protein reduction; and (3) indirect protein reduction such as methionine sulfoxide reductase (Msr) catalyzed reduction of methionine sulfoxide (MetO) residues on oxidized proteins; $\mathrm{ROOH}$, alkyl hydroperoxide; $\mathrm{ROH}$, alcohol; ROS, reactive oxygen species or other oxidant. 
<smiles>[R]n1c2nc(=O)[nH]c(=O)c-2nc2cc(C)c(C)cc21</smiles>

FAD (oxidized)<smiles>[R2]n1c2nc(=O)[nH]c(=O)c-2cc2ccc(O)cc21</smiles>

$F_{420}$ (oxidized)
$2 \mathrm{H}^{+}, 2 \mathrm{e}^{-}$<smiles></smiles>

$\mathrm{FADH}_{2}$ (reduced)<smiles>[R]N1c2cc(O)ccc2Cc2c1[nH]c(=O)[nH]c2=O</smiles>

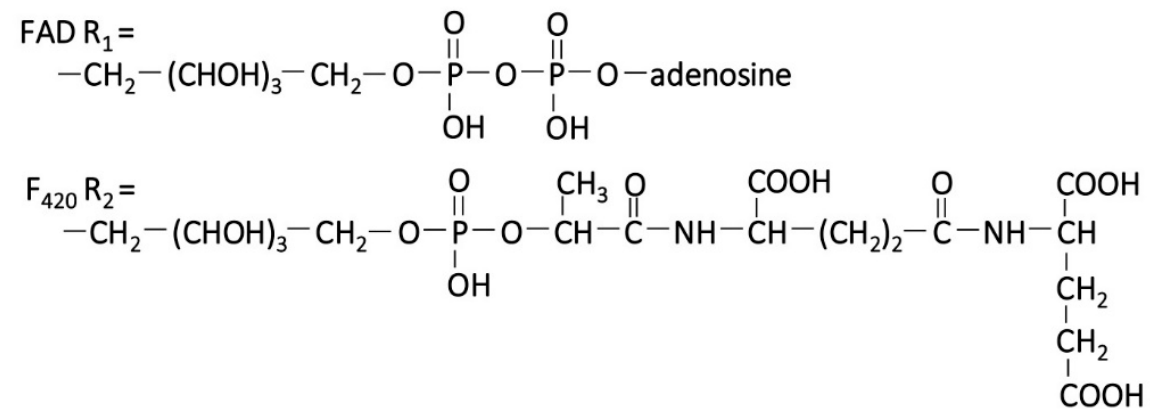

Figure 4. Comparison of coenzyme $\mathrm{F}_{420}$ and FAD oxidized and reduced forms.

\section{Thiol-Dependent Peroxidases}

One of the critical functions of LMW thiols is the reduction of oxidants. In eukaryotes, GSH peroxidases, GPX(s), are able to detoxify organic hydroperoxides, such as lipid peroxides [65]. The general absence of polyunsaturated fatty acids in archaea and bacteria suggests that GSH-dependent thiol peroxidases evolved in eukaryotes in response to the need to protect against polyunsaturated fatty acid oxidation. Assays for GSH and $\gamma$ GC-dependent enzymes demonstrated an absence of peroxidase activity in bacteria and haloarchaea [63]. E. coli BtuE is the only bacterial enzyme sharing homology with the GPX family that has been shown to have GSH dependent peroxidase activity with $\mathrm{H}_{2} \mathrm{O}_{2}$; however, BtuE is able to use thioredoxin (TRX, see below) to reduce organic peroxides and prefers TRX over GSH for the reduction of $\mathrm{H}_{2} \mathrm{O}_{2}$ [66]. In addition, $\gamma \mathrm{GC}$ could serve as a cofactor for human GPx1-mediated $\mathrm{H}_{2} \mathrm{O}_{2}$ reduction with similar efficiency as GSH only at low concentrations of the thiols [67]. InterPro (IPR000889) search of GSH peroxidases yielded 102 archaeal hits (Figure 2) suggesting that either a GSH or $\gamma \mathrm{GC}$ dependent peroxidase may exist in archaea. Peroxiredoxins (Prxs), thiol-dependent peroxidases that scavenge peroxides, have been identified in archaea [68-75]. In particular, the $S$. solfataricus Prx is shown to use a thiol relay system in which the GRX-like PDO accepts reductant from NTR to reactivate the Prx in its catalytic cycle [68-76].

\section{Protein S-Thiolation/Dethiolation in Protection and Signaling}

A major role for GRXs and GRX analogues is the S-thiolation/dethiolation of proteins $[77,78]$. $S$-thiolation is the formation of a mixed disulfide of cysteine with a LMW thiol, such as GSH (S-glutathionylation), BSH (S-bacillithiolation), or MSH (S-mycothiolation). $S$-thiolation has emerged as a major post-translational modification (PTM) of protein cysteines. This PTM protects protein cysteines against permanent damage during oxidative stress when the reactive oxygen species oxidize the thiols ( $\mathrm{R}-\mathrm{SH})$ to reversible sulfenic acid $(\mathrm{R}-\mathrm{SOH})$ and further to irreversible sulfinic $\left(\mathrm{R}-\mathrm{SO}_{2} \mathrm{H}\right)$ and 
sulfonic $\left(\mathrm{R}-\mathrm{SO}_{3} \mathrm{H}\right)$ acid. The irreversible oxidation of $-\mathrm{SH}$ causes damage to protein function and LMW thiols like GSH prevent this by reacting with protein disulfides or the sulfenic acid arising from oxidative stress to form mixed disulfides. S-thiolation/dethiolation with its fast turnover rate can also act as a redox signal to turn on and off transcription of genes (see Section 3). Once the oxidative stress is removed, either GSH or other LMW thiol or GRXs and their LMW analogues catalyze the reduction of the mixed disulfide and remove the LMW thiol to restore the protein cysteine. $S$-thiolation has not been reported in archaea. However, since all aerobic organisms encounter oxidative stress, $S$-thiolation/dethiolation is expected to occur in archaea.

\section{Thiol-Dependent Glyoxalases}

An important function of LMW thiols that may predate protection against oxidative stress is the detoxification of xenobiotics and endogenously produced electrophiles. The LMW thiol nucleophilic attack on electrophiles can be performed chemically or catalyzed by enzymes. GSH and presumably other thiols react with aldehydes spontaneously to form a hemithioacetal adduct between GSH and 2-oxoaldehydes formed during carbon metabolism [45]. For example, during glycolysis glucose is split into 3-C triosephosphates, glyceraldehyde phosphate and dihydoxyacetone phosphate, which can isomerize to form methylglyoxal, an aldehyde of pyruvate (2-oxoaldehyde) that is a strong electrophile and thus cytotoxic. Methylglyoxal synthase further catalyzes the production of methylglyoxal from dihydroxyacetone phosphate. Methylglyoxal reacts with GSH to form S-lactoylglutathione, a reaction catalyzed by glyoxalase I (glyoxylase I). Glyoxalase II (glyoxylase II) hydrolyses S-lactoylglutathione to D-lactate and GSH.

While archaea use alternative pathways for central metabolism (e.g., methanogenesis, modified Entner-Doudoroff or modified Emden-Meyerhof-Parnas) [79,80], these microbes produce methylglyoxal and likely use LMW thiols to remove this intermediate based on the following evidence. Glyoxalase I/II (EC 4.4.1.5/EC 3.1.2.6) homologs are relatively common among archaea and most haloarchaea harbor methylglyoxal synthase (EC 4.2.3.3) homologs. Even, the methanogen M. jannaschii that does not harbor a methylglyoxal synthase homolog is still found to produce methylglyoxal through an alternative route as a biosynthetic intermediate of 6-deoxy-5-ketofructose-1-phosphate, a precursor of aromatic amino acids [81]. Oren and Gurevich [82] examined eight species of Halobacteriaceae for the presence of methylglyoxal synthase and glyoxalase activity. Glyoxalase activity was detected in all eight species while methylglyoxal synthase activity was detected in six out of the eight species. Haloferax volcanii extracts showed optimal glyoxalase activity at $\mathrm{pH} 7$ in the presence of $3 \mathrm{M} \mathrm{KCl}$ and GSH or $\gamma$ GC [82] revealing that LMW thiols could be used to remove cytotoxic electrophiles produced during metabolism.

\section{GSH Dependent Formaldehyde Dehydrogenases}

Another well-known reactive aldehyde, formaldehyde, is also endogenously produced as a result of catabolism of methionine, methanol, and glyoxalate, or the oxidative demethylation of DNA and RNA. Formaldehyde is toxic [83] and can react with GSH spontaneously or enzymatically (in some eukaryotes and bacteria by S-(hydroxymethyl)glutathione synthase (EC 4.4.1.22)) to produce S-hydroxymethylglutathione (S-HMGSH) [84,85]. S-HMGSH is less toxic than formaldehyde and is recycled through oxidation by $S$-HMGSH dehydrogenase (EC 1.1.1.284) to generate $S$-formylglutathione and $\mathrm{NAD}(\mathrm{P}) \mathrm{H}$ [86]. Based on KEGG classification to EC 1.1.1.284, this enzyme appears common to eukaryotes and bacteria but rare in archaea. S-formylglutathione hydrolases (FGSH, EC 3.1.2.12) subsequently hydrolyze the $S$-formylglutathione to GSH and formate. While diverse in primary sequence, FGSHs have a canonical alpha/beta-hydrolase fold and serine hydrolase catalytic triad as exemplified by E. coli FrmB and YeiG and yeast YJL068C (PDB: 1pv1) [87]. Based on InterPro family IPR014186 classification, FGSHs appear more common in eukaryotes and bacteria than archaea, with the 40 archaeal hits primarily from the Sulfolobaceae family (Figure 2). Thus, an alternative route is likely used to mediate formaldehyde detoxification in archaea. 


\section{Glutathione S-Transferases}

A superfamily of enzymes, glutathione S-transferases (GST), are involved in detoxification and metabolism of endogenous compounds and defense against oxidative stress [88-90]. This GST superfamily consists of numerous enzyme classes with different types of reactions, such as nucleophilic aromatic substitution, nucleophilic addition and substitution, conjugate addition, epoxide ring opening, thiolysis, isomerization, and hydrolytic dehydrogenation. GSTs can also act as disulfide bond reductases, dehydroascorbate reductases, peroxidases, thiocyanate reductases, reductive dehalogenases, and alkylarsenate reductases. Moreover, GSTs can be involved in deglutathionylation of protein cysteines. GSTs are not closely related in sequence similarity but share a structural similarity, with a TRX-like N-terminal domain, which binds GSH and a C-terminal domain, which binds the substrate. Mashiyama and colleagues [91] constructed a network based on structural and sequence similarity from 13,000 cytoplasmic GST sequences, including archaeal sequences [91]. Sixteen proteins from the haloarchaea (Halobacteria class) fell into the subgroup Xi.1, which consists of GSTs with $S$-glutathionyl- $p$-hydroquinone reductase activity [91]. Interestingly, these enzymes can catalyze GSH-dependent thioltransferase reactions and deglutathionylation reactions along with reduction of GS-hydroquinones to hydroquinones [92]. An InterPro search also yielded 381 archaeal homologs that clustered to the GST-Omega family, IPR016639, which contains glutathionyl-p-hydroquinone reductase (Figure 2). Oztetik and Cakir (2013) [93] demonstrated that Haloarcula hispanica contained both GSH and had GST activity with 1-chloro-2,4-dinitrobenzene (CDNB), a classic GST substrate. Analysis of the $H$. hispanica genome reveals the presence of $g s h A$, at least three GSTs, and GRX homologs. No GshB is apparent. As the GSH concentration was determined using Ellman's reagent ((5,5'-dithiobis-(2-nitrobenzoic acid) or DTNB)), which would oxidize all -SH groups, including that of $\gamma \mathrm{GC}$, it is likely that the LMW thiol that was measured was $\gamma \mathrm{GC}$ and not GSH. Recently, the purification, crystallization, and structure determination of NmGHR, a GST of the Xi class from the extreme haloalkaliphilic archaeon Natrialba magadii ATCC 43099 was reported [94]. NmGHR activity was examined using $\gamma$ GC and GSH as co-substrates with: (i) benzoquinone as a substrate for glutathionyl- $p$-hydroquinone reductase activity, (ii) CDNB and ethacrynic acid as substrates for GST activity, and (iii) docosahexaenoic acid (DHA) and bis(2-hydroxyethyl) disulfide (HED) as substrates for thioltransferase activity. No activity was detected for any of these substrates; whether this is due to the method used to purify the enzyme (e.g., His tag, E. coli host) or the choice of substrates remains to be determined [94].

\section{GSH Metabolism}

Gamma-glutamyltranspeptidases (GGTs; EC 2.3. 2.2) catalyze the transfer of $\gamma$-glutamyl functional groups from GSH to an acceptor that may be an amino acid, a peptide or water (forming glutamate). GGTs play a key role in degradation of GSH and 224 members of the GGT InterPro family (IPR000101) classify to archaea. The S. solfataricus GGT homolog SSO_3216 increases in abundance following oxidative challenge [95]. Heinemann et al. (2014) further reported that S. solfataricus GGT reacts with GSH, although primarily in the oxidized form [95]. A closer look the sample preparation indicated that the $S$. solfataricus cells were lysed with a combination of freeze/thaw cycles, and protein samples were prepared from the resulting cell suspension. For metabolite analysis, cell pellets were resuspended in methanol, chloroform was added, and the samples were shaken for $2 \mathrm{~h}$ at $0{ }^{\circ} \mathrm{C}$. In both cases, the LMW thiol including protein cysteine and GSH are likely to oxidize. The low levels of GSH detected could have also been contamination from the media since the media for growth, DSMZ, contains yeast extract. Ignicoccus hospitalis gave similar results. Neither I. hospitalis nor S. solfataricus have homologs that classify to GshA, GshB or GshAB (GshF) InterPro families, although S. solfataricus SSO_2815 has low, but significant sequence similarity (43\% similarity, 23\% identity) with the M. stadtmanae GshA [95]. 


\section{Thiol/Disulfide Switches in Archaea}

Disulfide bond formation between cysteine residues and reduction of the disulfide bond acting as an on-off redox switch for transcriptional regulation is demonstrated in bacteria and eukaryotes [96,97]. In bacteria, the transcriptional regulator OxyR is involved in oxidative stress protection [98]. Oxidative stress causes disulfide bonds to form in OxyR, which changes its oligomerization and binding affinity [99]. Oxidized OxyR binds more readily to various promoters, and activates antioxidant genes [99]. The disulfides in OxyR are preferentially reduced by GRX 1 in vivo although TRX is also able to perform the same function in E. coli [100]. In OhrR, another transcriptional factor involved in oxidative stress protection, a key cysteine residue becomes $S$-bacillithiolated upon oxidative stress [101], i.e., the LMW thiol, BSH, forms a disulfide bond with the cysteine. The S-bacillithiolated OhrR repressor is inactive, which leads to the induction of expression of the gene encoding OhrA, a peroxiredoxin that can detoxify lipid peroxides [102]. The removal of the BSH is performed by bacilliredoxins, analogues of GRXs [78]. A redox switch can also be a part of bacterial two component systems (TCS); for example, the kinase RegB from Rhodobacter capsulatus is inactivated by disulfide bond formation under oxidizing conditions [103].

In the archaeal order Thermococcales, the sulfur response regulator, SurR, has a thiol-disulfide redox switch that allows Thermococcales such as Pyrococcus furiosus to change between two different metabolic modes. P. furiosus produces hydrogen gas in the absence of elemental sulfur $\left(\mathrm{S}^{0}\right)$ and $\mathrm{H}_{2} \mathrm{~S}$ in the presence of $S^{0}[104,105]$. SurR contains a CXXC motif that functions as a redox-active switch that controls its DNA binding affinity [106]. Oxidation of cysteines with $S^{0}$ inhibits DNA binding by SurR, leading to deactivation of genes related to $\mathrm{H}_{2}$ production and derepression of genes involved in $\mathrm{S}^{0}$ metabolism [107]. The oxidation can be reversed by addition of excess dithiothreitol (DTT), a reducing agent. Lim et al. (2017) demonstrated that the in vivo reductant is a protein disulfide oxidoreductase in Thermococcus onnurineus NA1 [108]. Interestingly, two of the three TRXs that were tested did not reduce SurR [108] suggesting protein substrate specificity within the TRX systems.

Another redox sensitive transcriptional regulator, MsvR, has been described in the strict methanogenic anaerobes, Methanosarcina acetivorans and Methanothermobacter thermautotrophicus. MsvR displays differential DNA binding under oxidizing and reducing conditions in both of these archaea $[109,110]$. In $M$. acetivorans, treatment of MsvR with $\mathrm{H}_{2} \mathrm{O}_{2}$ results in oxidation of cysteine thiols, preventing binding of MsvR to promoters. Incubation of oxidized MsvR with the M. acetivorans TRX system, consisting of NADPH, TRX reductase and one of the 7 TRXs, leads to reduction of the cysteines and binding to its own promoter [111].

Redox signaling also appears to occur through a thiol-dependent phosphorylation cascade in methanogens. Feige and Frankenberg-Dinkel [112] find that RdmS, a tyrosine kinase with a heme cofactor, undergoes redox-dependent autophosphorylation in M. acetivorans. The heme cofactor does not affect RdmS autophosphorylation activity, and the autophosphorylation only occurs under oxidizing conditions [112]. An intramolecular disulfide bond is present in RdmS under oxidizing conditions, and incubation with DTT or CoM abrogates the autophosphorylation revealing the importance of disulfide bond(s) in this mechanism. The authors proposed that either the TRX/TRX reductase system or methanoredoxin may be the natural reductant for the disulfides.

\section{Coenzyme A in Archaea}

CoA has been suggested to be a major thiol in archaea, possibly due to the presence of disulfide reductases (CoADR) that reduce oxidized CoA denoting the ability of these cells to recycle CoA to its reduced form [113-115]. CoADR classify to the InterPro IPR017758 family and include 60 hits to hyperthermophilic archaea of the orders Sulfolobales and Thermococcales (Figure 2). In the hyperthermophilic archaea, Hummel et al. (2005) [116] measured CoA levels in units of $\mu \mathrm{mol} / \mathrm{g}$ dry weight at 1.54 in Thermococcus litoralis, 0.98 in P. furiosus, and 0.4 in S. solfataricus. In addition, these authors reported that growth on sulfur increased the CoA levels in these organisms [116]. The CoADRs from $P$. horikoshii and $P$. furiosus are able to use both NADPH and NADH as substrates, unlike the 
mesophilic bacterial CoADR of Staphylococcus aureus [117]. However, several questions remain as to how CoA could assume the protective functions of a LMW thiol. CoA cannot be used as a storage form of cysteine, since the Cys moiety is decarboxylated during CoA biosynthesis. Furthermore, while an unusual NADPH-dependent disulfide reductase with a high affinity for CoA disulfide, which would maintain CoA in a reduced condition, is present in S. aureus [113] and B. anthracis [118], it is absent in other related species, such as $B$. subtilis. Finally, the $\mathrm{pKa}$ of the CoA thiol is very basic $(\mathrm{pH}=10)$ indicating that it is unable to participate in oxidation and reduction reactions. The arguments for CoA serving as the major LMW thiol are: i) It is more resistant to auto-oxidation than cysteine and GSH and ii) it is more stable than GSH in the presence of copper, even at high temperatures [113].

\section{MSH in Archaea}

In high GC actinobacteria, MSH is the major thiol. MSH has an acetylated cysteine with the amino group forming an amide bond with glucosamine, which is linked to inositol (Figure 1) [16,27,119,120]. MSH biosynthesis proceeds through a five-step pathway [119]. The initial substrates, 1L-myo-inositol-1-monophosphate and UDP-N-acetylglucosamine, react to form $N$-acetylglucosaminylinositol phosphate; this reaction is catalyzed by the $N$-acetylglucosamine transferase, MshA [121,122]. An unidentified phosphatase dephosphorylates this molecule to yield N-acetylglucosaminylinositol, which is deacetylated by an MshB deacetylase [123]. The resulting glucosaminylinositol is ligated with L-cysteine in a reaction catalyzed by a ligase, MshC (IPR017812) [124,125]. The cysteinylglucosaminylinositol is then acetylated to form MSH in a reaction catalyzed by MshD acetyltransferase (IPR017813) [126]. Mca, mycothiol conjugate amidase (IPR017811), catalyzes the cleavage of the amide bond between an electrophile and glucosamine and, thus, plays a major role in MSH dependent detoxification and recycling of MSH [127,128]. Mtr, mycothione reductase (IPR017817), catalyzes the NADPH dependent reduction of oxidized MSH [129]. InterPro analysis of these MSH-related gene homologs reveals only a single hit for MshD (IPR017813) in uncultivated samples. MSH has also not been detected in archaea. This absence of MSH and absence of gene homologs involved in MSH metabolism indicates clearly that MSH is not present in archaea thus far sequenced.

\section{BSH in Archaea}

In low GC Gram positive bacteria, such as the Firmicutes, BSH (Figure 1) is the major LMW thiol. $\mathrm{BSH}$ is structurally similar to MSH in that it contains the core cysteinylglucosamine moiety [130]. However, BSH does not contain the $\mathrm{N}$-acetyl residue at the cysteine and the cysteinylglucosamine is linked to L-malate instead of the inositol. Because BSH shares the common cysteinylglucosamine moiety as MSH, the BSH biosynthesis pathway shares a common biosynthetic process to MSH. The first enzymatic reaction was identified as consisting of the joining of UDP-N-acetylglucosamine to L-malate catalyzed by a glycosyltransferase (BshA) to yield $N$-acetylglucosaminylmalate (GlcNAcMal) [131] . Next, a deacetylase (BshB) deacetylates GlcNAc-Mal to yield glucosaminylmalate (GlcN-Mal) [132]. The third enzymatic reaction was proposed to involve the ligation of L-cysteine to GlcNAc-Mal to form $\mathrm{BSH}$, a reaction catalyzed by a BSH synthetase (BshC) [133,134]. InterPro search of BshA (IPR023881) and BshC (IPR011199) homologs in archaea resulted in 39 hits for each enzyme, with the majority of hits clustering to the Asgard (an archaeal superphylum with close ties to the last common eukaryotic ancestor [135]). A search for the recently identified BSH disulfide reductase, Ypd, resulted in only two gene homologs in archaea (IPR023856) [136,137]. BSH has not been detected in archaea but Asgard archaea have only recently been cultivated [138], and the presence of BshA and BshC homologs suggests that archaea may be capable of synthesizing BSH.

\section{Aerobic and Anaerobic Biosynthesis of EGT in Archaea}

Another LMW thiol that is common in bacteria is EGT (Figure 1). EGT is a thiourea derivative of histidine, containing a sulfur atom on the imidazole ring, that exists as a thione under physiological 
conditions [139]. Synthesis of EGT was first elucidated in mycobacteria where the biosynthetic genes are present in a five gene cluster (egt $A B C D E$ ) [11]. First, similar to GSH synthesis, synthesis of $\gamma \mathrm{GC}$ is catalyzed by EgtA. Hercynine is formed by the methylation of L-histidine, a reaction catalyzed by a methyltransferase (EgtD). EgtB then catalyzes the addition of $\gamma \mathrm{GC}$ to hercynine to form hercynal $\gamma \mathrm{GC}$ sulfoxide. Glutamate is removed by a glutamine amidotransferase $(\mathrm{EgtC})$ to form hercynlcysteine sulfoxide. Finally, a pyridoxal 5-phosphate-dependent $\beta$-lyase (EgtE) converts hercynlcysteine to EGT. Phylogenetic studies of fungal and bacterial species reveal that synthesis of EGT might not require all five steps. For example, cyanobacteria produce high levels of ergothioneine without orthologs to egtC, or egtE [140]. In fact, a survey of over 2,500 bacteria showed that the five gene cluster was specific to Actinobacteria and only EgtB and EgtD are the key enzymes for EGT synthesis. The functions of EgtA, $\mathrm{EgtC}$, and EgtE are potentially performed by other unknown enzymes or are not needed since the source of sulfur differs from $\gamma$ GC to cysteine [141]. EgtB (IPR017806) and EgtD (IPR035094) homologs are present in archaea (104 for EgtB and 118 for EgtD) suggesting that EGT may be synthesized in some archaeal species.

Recently, Seebeck and colleagues reported the anaerobic synthesis of EGT $[142,143]$. The green sulfur bacterium Chlorobium limicola encodes a sulfur transferase EanB (Clim_1149, PDB: 6H9A) that converts trimethylhistidine into EGT using oxygen-independent chemistry. The rhodanese-like enzyme transfers sulfur to a non-activated carbon of the trimethylhistidine [143]. The EanA methyltransferase (Clim_1148) converts histidine to trimethylhistidine to initiate this pathway. In archaea, homologs of EanA and EanB are present particularly in anaerobic methanogens. Methanococcoides vulcani SAMN04488587_0183 contains an EanA like domain and SAMN04488587_0184 contains a rhodanese domain reminiscent of a sulfur transferase EanB; thus, genome synteny providing further support for this relationship to EGT biosynthesis. The presence of the EGT biosynthesis genes (aerobic and anaerobic) suggests that EGT may play a role in archaea even though this LMW thiol has not been detected in archaea.

\section{Conclusions and Future Directions}

Herein, we show that: (i) $\gamma \mathrm{GC}$ is likely the major thiol in haloarchaea and is likely present in methanogens, (ii) CoA is the major thiol in hyperthermophiles, (iii) BSH may be present in archaea due to the presence of BSH biosynthesis genes, and (iv) similarly, EGT may also be present in archaea as both aerobic- and anaerobic-type EGT biosynthesis genes are detected among the archaeal genomic sequences. In addition, novel thiols with unique structures and functions are likely to also be present in archaea. These LMW thiols may not be easily discovered by interrogating just genomic sequences but will require purification and structural characterization of the compound. A better understanding of the structure and function of LMW thiols in archaea will open up novel biochemistries which explain how archaea are able to adapt to extreme environments.

Supplementary Materials: The following are available online at http://www.mdpi.com/2076-3921/9/5/381/s1, Table S1: Supporting information for analysis of archaeal homologs presented in Figure 2.

Author Contributions: Each author contributed equally to the work. All authors have read and agreed to the published version of the manuscript.

Funding: Work in MR's laboratory on LMW thiols is supported by the National Institutes of Health SC3GM-100855-03 and National Science Foundation grant MCB1244611. JMF's work is supported by the U.S. Department of Energy, Office of Basic Energy Sciences, Division of Chemical Sciences, Geosciences and Biosciences, Physical Biosciences Program (DOE DE-FG02-05ER15650) to advance applications of archaea in bioenergy, the National Institutes of Health (NIH R01 GM57498) to reveal systems important to human health through study of archaea, and the National Science Foundation (MCB-1642283) for systems analysis of archaeal cell biology.

Conflicts of Interest: The authors declare no conflict of interest. 


\begin{abstract}
Abbreviations
LMW, low molecular weight; $\gamma \mathrm{GC}, \gamma$-glutamylcysteine; MSH, mycothiol; CoA, coenzyme A; BSH, bacilithiol; EGT, ergothioneine; GSH, glutathione or $\gamma$-L-glutamyl-L-cysteinylglycine; GCR, $\gamma$-glutamylcysteine reductase; $\gamma$-ECL, $\gamma$-glutamate-cysteine ligase or synthetase; GS, glutathione synthetase; GshF or GshAB, $\gamma$-glutamate-cysteine ligase/glutathione synthetase fusion protein; DHD, dihydrolipoamide dehydrogenase; GGT, gamma-glutamyltranspeptidase; GST, glutathione S-transferase; GPX, glutathione peroxidase; CDNB, 1-chloro-2,4-dinitrobenzene; DTT, dithiothreitol; PTM, posttranslational modification; S-HMGSH, $S$-(hydroxymethyl)glutathione; FGSH, formylglutathione hydrolase; $\mathrm{NAD}(\mathrm{P}) \mathrm{H}$, nicotinamide adenine dinucleotide (phosphate) hydrogen; CoM, coenzyme M or 2-sulfanylethanesulfonate; CoMS-SCoM, coenzyme M disulfide; $\mathrm{CoB}$, coenzyme B or 7-mercaptoheptanoylthreoninephosphate; FAD, flavin adenine dinucleotide; coenzyme F420, 8-hydroxy-5-deazaflavin; UDP, uridine diphosphate; GRX, glutaredoxin; TRX, thioredoxin; MRX, methanoredoxin; PDO, protein disulfide oxidoreducatase.
\end{abstract}

\title{
References
}

1. Fahey, R.C. Glutathione analogs in prokaryotes. Biochim. Biophys. Acta 2013, 1830, 3182-3198. [CrossRef] [PubMed]

2. Korshunov, S.; Imlay, K.R.C.; Imlay, J.A. Cystine import is a valuable but risky process whose hazards Escherichia coli minimizes by inducing a cysteine exporter. Mol. Microbiol. 2020, 113, 22-39. [CrossRef] [PubMed]

3. Bagiyan, G.A.; Koroleva, I.K.; Soroka, N.V.; Ufimtsev, A.V. Oxidation of thiol compounds by molecular oxygen in aqueous solutions. Russ. Chem. Bull 2003, 52, 1135-1141. [CrossRef]

4. Masip, L.; Veeravalli, K.; Georgiou, G. The many faces of glutathione in bacteria. Antioxid. Redox Signal. 2006, 8, 753-762. [CrossRef]

5. Posada, A.C.; Kolar, S.L.; Dusi, R.G.; Francois, P.; Roberts, A.A.; Hamilton, C.J.; Liu, G.Y.; Cheung, A. Importance of bacillithiol in the oxidative stress response of Staphylococcus aureus. Infect. Immun. 2014, 82, 316-332. [CrossRef]

6. Ramsay, E.E.; Dilda, P.J. Glutathione S-conjugates as prodrugs to target drug-resistant tumors. Front. Pharmacol. 2014, 5, 181. [CrossRef]

7. Jozefczak, M.; Remans, T.; Vangronsveld, J.; Cuypers, A. Glutathione is a key player in metal-induced oxidative stress defenses. Int. J. Mol. Sci. 2012, 13, 3145-3175. [CrossRef]

8. Holmgren, A.; Sengupta, R. The use of thiols by ribonucleotide reductase. Free Radic. Biol. Med. 2010, 49, 1617-1628. [CrossRef]

9. Maupin-Furlow, J.A. Methionine sulfoxide reductases of archaea. Antioxidants 2018, 7, 124. [CrossRef]

10. Liao, C.; Seebeck, F.P. Convergent evolution of ergothioneine biosynthesis in cyanobacteria. Chembiochem 2017, 18, 2115-2118. [CrossRef]

11. Seebeck, F.P. In vitro reconstitution of mycobacterial ergothioneine biosynthesis. J. Am Chem. Soc. 2010, 132, 6632-6633. [CrossRef] [PubMed]

12. Gamage, A.M.; Liao, C.; Cheah, I.K.; Chen, Y.; Lim, D.R.X.; Ku, J.W.K.; Chee, R.S.L.; Gengenbacher, M.; Seebeck, F.P.; Halliwell, B.; et al. The proteobacterial species Burkholderia pseudomallei produces ergothioneine, which enhances virulence in mammalian infection. FASEB J. 2018, fj201800716. [CrossRef] [PubMed]

13. Leroux, A.E.; Krauth-Siegel, R.L. Thiol redox biology of trypanosomatids and potential targets for chemotherapy. Mol. Biochem. Parasitol. 2016, 206, 67-74. [CrossRef] [PubMed]

14. Bartsch, R.G.; Newton, G.L.; Sherrill, C.; Fahey, R.C. Glutathione amide and its perthiol in anaerobic sulfur bacteria. J. Bacteriol. 1996, 178, 4742-4746. [CrossRef]

15. Fahey, R.C.; Newton, G.L. Determination of low-molecular-weight thiols using monobromobimane fluorescent labeling and high-performance liquid chromatography. Methods Enzymol. 1987, 143, 85-96. [CrossRef]

16. Newton, G.L.; Arnold, K.; Price, M.S.; Sherrill, C.; Delcardayre, S.B.; Aharonowitz, Y.; Cohen, G.; Davies, J.; Fahey, R.C.; Davis, C. Distribution of thiols in microorganisms: Mycothiol is a major thiol in most actinomycetes. J. Bacteriol. 1996, 178, 1990-1995. [CrossRef]

17. Vergauwen, B.; Pauwels, F.; Vaneechoutte, M.; Van Beeumen, J.J. Exogenous glutathione completes the defense against oxidative stress in Haemophilus influenzae. J. Bacteriol. 2003, 185, 1572-1581. [CrossRef] 
18. Vergauwen, B.; Verstraete, K.; Senadheera, D.B.; Dansercoer, A.; Cvitkovitch, D.G.; Guédon, E.; Savvides, S.N. Molecular and structural basis of glutathione import in Gram-positive bacteria via GshT and the cystine ABC importer TcyBC of Streptococcus mutans. Mol. Microbiol. 2013, 89, 288-303. [CrossRef]

19. Vergauwen, B.; De Vos, D.; Van Beeumen, J.J. Characterization of the bifunctional $\gamma$-glutamate-cysteine ligase/glutathione synthetase (GshF) of Pasteurella multocida. J. Biol. Chem. 2006, 281, 4380-4394. [CrossRef]

20. Imber, M.; Pietrzyk-Brzezinska, A.J.; Antelmann, H. Redox regulation by reversible protein $S$-thiolation in Gram-positive bacteria. Redox Biol. 2019, 20, 130-145. [CrossRef]

21. Fahey, R.C.; Newton, G.L.; Arrick, B.; Overdank-Bogart, T.; Aley, S.B. Entamoeba histolytica: A eukaryote without glutathione metabolism. Science 1984, 224, 70-72. [CrossRef]

22. Fahey, R.C.; Brown, W.C.; Adams, W.B.; Worsham, M.B. Occurrence of glutathione in bacteria. J. Bacteriol. 1978, 133, 1126-1129. [CrossRef] [PubMed]

23. Rocha, E.R.; Tzianabos, A.O.; Smith, C.J. Thioredoxin reductase is essential for thiol/disulfide redox control and oxidative stress survival of the anaerobe Bacteroides fragilis. J. Bacteriol. 2007, 189, 8015-8023. [CrossRef] [PubMed]

24. Lu, S.C. Glutathione synthesis. Biochim. Biophys. Acta 2013, 1830, 3143-3153. [CrossRef] [PubMed]

25. Gopal, S.; Borovok, I.; Ofer, A.; Yanku, M.; Cohen, G.; Goebel, W.; Kreft, J.; Aharonowitz, Y. A multidomain fusion protein in Listeria monocytogenes catalyzes the two primary activities for glutathione biosynthesis. J. Bacteriol. 2005, 187, 3839-3847. [CrossRef] [PubMed]

26. Vergauwen, B.; Pauwels, F.; Jacquemotte, F.; Meyer, T.E.; Cusanovich, M.A.; Bartsch, R.G.; Van Beeumen, J.J. Characterization of glutathione amide reductase from Chromatium gracile. Identification of a novel thiol peroxidase (Prx/Grx) fueled by glutathione amide redox cycling. J. Biol. Chem. 2001, 276, 20890-20897. [CrossRef]

27. Spies, H.S.; Steenkamp, D.J. Thiols of intracellular pathogens. Identification of ovothiol A in Leishmania donovani and structural analysis of a novel thiol from Mycobacterium bovis. Eur. J. Biochem. 1994, 224, $203-213$. [CrossRef]

28. Fairlamb, A.H.; Blackburn, P.; Ulrich, P.; Chait, B.T.; Cerami, A. Trypanothione: A novel bis(glutathionyl)spermidine cofactor for glutathione reductase in trypanosomatids. Science 1985, 227, 1485-1487. [CrossRef]

29. Newton, G.L.; Javor, B. $\gamma$-Glutamylcysteine and thiosulfate are the major low-molecular-weight thiols in halobacteria. J. Bacteriol. 1985, 161, 438-441. [CrossRef]

30. Gunde-Cimerman, N.; Plemenitaš, A.; Oren, A. Strategies of adaptation of microorganisms of the three domains of life to high salt concentrations. FEMS Microbiol. Rev. 2018, 42, 353-375. [CrossRef]

31. Sundquist, A.R.; Fahey, R.C. The function of $\gamma$-glutamylcysteine and bis- $\gamma$-glutamylcystine reductase in Halobacterium halobium. J. Biol. Chem. 1989, 264, 719-725. [PubMed]

32. Sundquist, A.R.; Fahey, R.C. The novel disulfide reductase bis- $\gamma$-glutamylcystine reductase and dihydrolipoamide dehydrogenase from Halobacterium halobium: Purification by immobilized-metal-ion affinity chromatography and properties of the enzymes. J. Bacteriol. 1988, 170, 3459-3467. [CrossRef] [PubMed]

33. Kim, J.; Copley, S.D. The orphan protein bis- $\gamma$-glutamylcystine reductase joins the pyridine nucleotide disulfide reductase family. Biochemistry 2013, 52, 2905-2913. [CrossRef] [PubMed]

34. van Ooyen, J.; Soppa, J. Three 2-oxoacid dehydrogenase operons in Haloferax volcanii: Expression, deletion mutants and evolution. Microbiology 2007, 153, 3303-3313. [CrossRef]

35. Bräsen, C.; Esser, D.; Rauch, B.; Siebers, B. Carbohydrate metabolism in Archaea: Current insights into unusual enzymes and pathways and their regulation. Microbiol. Mol. Biol. Rev. 2014, 78, 89-175. [CrossRef]

36. Malki, L.; Yanku, M.; Borovok, I.; Cohen, G.; Mevarech, M.; Aharonowitz, Y. Identification and characterization of $g \operatorname{sh} A$, a gene encoding the glutamate-cysteine ligase in the halophilic archaeon Haloferax volcanii. J. Bacteriol. 2009, 191, 5196-5204. [CrossRef]

37. Leahy, S.C.; Kelly, W.J.; Altermann, E.; Ronimus, R.S.; Yeoman, C.J.; Pacheco, D.M.; Li, D.; Kong, Z.; McTavish, S.; Sang, C.; et al. The genome sequence of the rumen methanogen Methanobrevibacter ruminantium reveals new possibilities for controlling ruminant methane emissions. PLoS ONE 2010, 5, e8926. [CrossRef]

38. Copley, S.D.; Dhillon, J.K. Lateral gene transfer and parallel evolution in the history of glutathione biosynthesis genes. Genome. Biol. 2002, 3, research0025. [CrossRef] 
39. Castelle, C.J.; Banfield, J.F. Major new microbial groups expand diversity and alter our understanding of the tree of life. Cell 2018, 172, 1181-1197. [CrossRef]

40. Vlamis-Gardikas, A.; Holmgren, A. Thioredoxin and glutaredoxin isoforms. Methods Enzymol. 2002, 347, 286-296. [CrossRef]

41. Martin, M.N.; Tarczynski, M.C.; Shen, B.; Leustek, T. The role of 5'-adenylylsulfate reductase in controlling sulfate reduction in plants. Photosynth. Res. 2005, 86, 309-323. [CrossRef] [PubMed]

42. Hugo, M.; Van Laer, K.; Reyes, A.M.; Vertommen, D.; Messens, J.; Radi, R.; Trujillo, M. Mycothiol/mycoredoxin 1-dependent reduction of the peroxiredoxin AhpE from Mycobacterium tuberculosis. J. Biol. Chem. 2014, 289, 5228-5239. [CrossRef] [PubMed]

43. Wells, W.W.; Yang, Y.; Deits, T.L.; Gan, Z.R. Thioltransferases. Adv. Enzymol. Relat. Areas Mol. Biol. 1993, 66, 149-201. [CrossRef] [PubMed]

44. Xiao, Z.; La Fontaine, S.; Bush, A.I.; Wedd, A.G. Molecular mechanisms of glutaredoxin enzymes: Versatile hubs for thiol-disulfide exchange between protein thiols and gutathione. J. Mol. Biol. 2019, 431, 158-177. [CrossRef]

45. Deponte, M. Glutathione catalysis and the reaction mechanisms of glutathione-dependent enzymes. Biochim. Biophys. Acta 2013, 1830, 3217-3266. [CrossRef]

46. Lu, J.; Holmgren, A. The thioredoxin antioxidant system. Free Radic. Biol. Med. 2014, 66, 75-87. [CrossRef]

47. Jung, H.C.; Lim, J.K.; Yang, T.J.; Kang, S.G.; Lee, H.S. Direct electron transfer between the frhAGB-encoded hydrogenase and thioredoxin reductase in the nonmethanogenic archaeon Thermococcus onnurineus NA1. Appl. Environ. Microbiol. 2020, 86. [CrossRef]

48. Susanti, D.; Loganathan, U.; Mukhopadhyay, B. A novel F420-dependent thioredoxin reductase gated by low potential FAD: A tool for redox regulation in an anaerobe. J. Biol. Chem. 2016, 291, 23084-23100. [CrossRef]

49. Buey, R.M.; Fernández-Justel, D.; de Pereda, J.M.; Revuelta, J.L.; Schürmann, P.; Buchanan, B.B.; Balsera, M. Ferredoxin-linked flavoenzyme defines a family of pyridine nucleotide-independent thioredoxin reductases. Proc. Natl. Acad. Sci. USA 2018, 115, 12967-12972. [CrossRef]

50. Prakash, D.; Walters, K.A.; Martinie, R.J.; McCarver, A.C.; Kumar, A.K.; Lessner, D.J.; Krebs, C.; Golbeck, J.H.; Ferry, J.G. Toward a mechanistic and physiological understanding of a ferredoxin:disulfide reductase from the domains Archaea and Bacteria. J. Biol. Chem. 2018, 293, 9198-9209. [CrossRef]

51. Grimaldi, P.; Ruocco, M.R.; Lanzotti, M.A.; Ruggiero, A.; Ruggiero, I.; Arcari, P.; Vitagliano, L.; Masullo, M. Characterisation of the components of the thioredoxin system in the archaeon Sulfolobus solfataricus. Extremophiles 2008, 12, 553-562. [CrossRef] [PubMed]

52. Ruocco, M.R.; Ruggiero, A.; Masullo, L.; Arcari, P.; Masullo, M. A 35 kDa NAD(P)H oxidase previously isolated from the archaeon Sulfolobus solfataricus is instead a thioredoxin reductase. Biochimie 2004, 86, 883-892. [CrossRef] [PubMed]

53. Jeon, S.J.; Ishikawa, K. Identification and characterization of thioredoxin and thioredoxin reductase from Aeropyrum pernix K1. Eur. J. Biochem. 2002, 269, 5423-5430. [CrossRef] [PubMed]

54. Kashima, Y.; Ishikawa, K. A hyperthermostable novel protein-disulfide oxidoreductase is reduced by thioredoxin reductase from hyperthermophilic archaeon Pyrococcus horikoshii. Arch Biochem. Biophys. 2003, 418, 179-185. [CrossRef] [PubMed]

55. Pedone, E.; Limauro, D.; D'Alterio, R.; Rossi, M.; Bartolucci, S. Characterization of a multifunctional protein disulfide oxidoreductase from Sulfolobus solfataricus. FEBS J. 2006, 273, 5407-5420. [CrossRef] [PubMed]

56. McCarver, A.C.; Lessner, F.H.; Soroeta, J.M.; Lessner, D.J. Methanosarcina acetivorans utilizes a single NADPH-dependent thioredoxin system and contains additional thioredoxin homologues with distinct functions. Microbiology 2017, 163, 62-74. [CrossRef] [PubMed]

57. Susanti, D.; Wong, J.H.; Vensel, W.H.; Loganathan, U.; DeSantis, R.; Schmitz, R.A.; Balsera, M.; Buchanan, B.B.; Mukhopadhyay, B. Thioredoxin targets fundamental processes in a methane-producing archaeon, Methanocaldococcus jannaschii. Proc. Natl. Acad. Sci. USA 2014, 111, 2608-2613. [CrossRef]

58. Lee, D.Y.; Ahn, B.Y.; Kim, K.S. A thioredoxin from the hyperthermophilic archaeon Methanococcus jannaschii has a glutaredoxin-like fold but thioredoxin-like activities. Biochemistry 2000, 39, 6652-6659. [CrossRef]

59. McFarlan, S.C.; Terrell, C.A.; Hogenkamp, H.P. The purification, characterization, and primary structure of a small redox protein from Methanobacterium thermoautotrophicum, an archaebacterium. J. Biol. Chem. 1992, $267,10561-10569$. 
60. Yenugudhati, D.; Prakash, D.; Kumar, A.K.; Kumar, R.S.; Yennawar, N.H.; Yennawar, H.P.; Ferry, J.G. Structural and biochemical characterizations of methanoredoxin from Methanosarcina acetivorans, a glutaredoxin-like enzyme with coenzyme M-dependent protein disulfide reductase activity. Biochemistry 2016, 55, 313-321. [CrossRef]

61. Yan, Z.; Ferry, J.G. Electron bifurcation and confurcation in methanogenesis and reverse methanogenesis. Front. Microbiol. 2018, 9, 1322. [CrossRef] [PubMed]

62. Smith, S.G.; Rouviere, P.E. Purification and characterization of the reduced-nicotinamide-dependent 2,2'-dithiodiethanesulfonate reductase from Methanobacterium thermoautotrophicum delta H. J. Bacteriol. 1990, 172, 6435-6441. [CrossRef] [PubMed]

63. Sundquist, A.R.; Fahey, R.C. Evolution of antioxidant mechanisms: Thiol-dependent peroxidases and thioltransferase among procaryotes. J. Mol. Evol. 1989, 29, 429-435. [CrossRef] [PubMed]

64. Gellert, M.; Hossain, M.F.; Berens, F.J.F.; Bruhn, L.W.; Urbainsky, C.; Liebscher, V.; Lillig, C.H. Substrate specificity of thioredoxins and glutaredoxins - towards a functional classification. Heliyon 2019, 5, e02943. [CrossRef] [PubMed]

65. Flohé, L.; Toppo, S.; Cozza, G.; Ursini, F. A comparison of thiol peroxidase mechanisms. Antioxid. Redox Signal. 2011, 15, 763-780. [CrossRef] [PubMed]

66. Arenas, F.A.; Díaz, W.A.; Leal, C.A.; Pérez-Donoso, J.M.; Imlay, J.A.; Vásquez, C.C. The Escherichia coli btuE gene, encodes a glutathione peroxidase that is induced under oxidative stress conditions. Biochem. Biophys. Res. Commun. 2010, 398, 690-694. [CrossRef]

67. Quintana-Cabrera, R.; Fernandez-Fernandez, S.; Bobo-Jimenez, V.; Escobar, J.; Sastre, J.; Almeida, A.; Bolaños, J.P. $\gamma$-Glutamylcysteine detoxifies reactive oxygen species by acting as glutathione peroxidase-1 cofactor. Nat. Commun. 2012, 3, 718. [CrossRef]

68. Lee, S.; Jia, B.; Liu, J.; Pham, B.P.; Kwak, J.M.; Xuan, Y.H.; Cheong, G.W. A 1-Cys peroxiredoxin from a thermophilic archaeon moonlights as a molecular chaperone to protect protein and DNA against stress-induced damage. PLoS ONE 2015, 10, e0125325. [CrossRef]

69. Dokainish, H.M.; Simard, D.J.; Gauld, J.W. A pseudohypervalent sulfur intermediate as an oxidative protective mechanism in the achaea peroxiredoxin enzyme ApTPx. J. Phys. Chem. B 2017, 121, 6570-6579. [CrossRef]

70. Stroobants, S.; Van Molle, I.; Saidi, Q.; Jonckheere, K.; Maes, D.; Peeters, E. Structure of the Prx6-subfamily 1-Cys peroxiredoxin from Sulfolobus islandicus. Acta Crystallogr. F Struct. Biol. Commun. 2019, 75, 428-434. [CrossRef]

71. Nakamura, T.; Mori, A.; Niiyama, M.; Matsumura, H.; Tokuyama, C.; Morita, J.; Uegaki, K.; Inoue, T. Structure of peroxiredoxin from the anaerobic hyperthermophilic archaeon Pyrococcus horikoshii. Acta Crystallogr. Sect. F Struct. Biol. Cryst. Commun. 2013, 69, 719-722. [CrossRef] [PubMed]

72. Limauro, D.; D'Ambrosio, K.; Langella, E.; De Simone, G.; Galdi, I.; Pedone, C.; Pedone, E.; Bartolucci, S. Exploring the catalytic mechanism of the first dimeric Bcp: Functional, structural and docking analyses of Bcp4 from Sulfolobus solfataricus. Biochimie 2010, 92, 1435-1444. [CrossRef] [PubMed]

73. Nakamura, T.; Kado, Y.; Yamaguchi, T.; Matsumura, H.; Ishikawa, K.; Inoue, T. Crystal structure of peroxiredoxin from Aeropyrum pernix K1 complexed with its substrate, hydrogen peroxide. J. Biochem. 2010, 147, 109-115. [CrossRef] [PubMed]

74. Kashima, Y.; Ishikawa, K. Alkyl hydroperoxide reductase dependent on thioredoxin-like protein from Pyrococcus horikoshii. J. Biochem. 2003, 134, 25-29. [CrossRef]

75. Sarcinelli, C.; Fiorentino, G.; Pizzo, E.; Bartolucci, S.; Limauro, D. Discovering antioxidant molecules in the Archaea domain: Peroxiredoxin Bcp1 from Sulfolobus solfataricus protects H9c2 cardiomyoblasts from oxidative stress. Archaea 2016, 2016, 7424870. [CrossRef]

76. D'Ambrosio, K.; Limauro, D.; Pedone, E.; Galdi, I.; Pedone, C.; Bartolucci, S.; De Simone, G. Insights into the catalytic mechanism of the Bcp family: Functional and structural analysis of Bcp1 from Sulfolobus solfataricus. Proteins 2009, 76, 995-1006. [CrossRef]

77. Matsui, R.; Ferran, B.; Oh, A.; Croteau, D.; Shao, D.; Han, J.; Pimentel, D.R.; Bachschmid, M.M. Redox regulation via glutaredoxin-1 and protein S-glutathionylation. Antioxid. Redox Signal. 2020, 32, 677-700. [CrossRef] 
78. Gaballa, A.; Chi, B.K.; Roberts, A.A.; Becher, D.; Hamilton, C.J.; Antelmann, H.; Helmann, J.D. Redox regulation in Bacillus subtilis: The bacilliredoxins $\operatorname{BrxA}(\mathrm{YphP})$ and $\operatorname{BrxB}(\mathrm{YqiW})$ function in de-bacillithiolation of S-bacillithiolated OhrR and MetE. Antioxid. Redox Signal. 2014, 21, 357-367. [CrossRef]

79. Siebers, B.; Schönheit, P. Unusual pathways and enzymes of central carbohydrate metabolism in Archaea. Curr. Opin. Microbiol. 2005, 8, 695-705. [CrossRef]

80. Ronimus, R.S.; Morgan, H.W. Distribution and phylogenies of enzymes of the Embden-Meyerhof-Parnas pathway from archaea and hyperthermophilic bacteria support a gluconeogenic origin of metabolism. Archaea 2003, 1, 199-221. [CrossRef]

81. White, R.H.; Xu, H. Methylglyoxal is an intermediate in the biosynthesis of 6-deoxy-5-ketofructose1-phosphate: A precursor for aromatic amino acid biosynthesis in Methanocaldococcus jannaschii. Biochemistry 2006, 45, 12366-12379. [CrossRef] [PubMed]

82. Oren, A.; Gurevich, P. Occurrence of the methylglyoxal bypass in halophilic Archaea. FEMS Microbiol. Lett. 1995, 125, 83-87. [CrossRef]

83. Grafstrom, R.C.; Fornace, A.J.; Autrup, H.; Lechner, J.F.; Harris, C.C. Formaldehyde damage to DNA and inhibition of DNA repair in human bronchial cells. Science 1983, 220, 216-218. [CrossRef]

84. Goenrich, M.; Bartoschek, S.; Hagemeier, C.H.; Griesinger, C.; Vorholt, J.A. A glutathione-dependent formaldehyde-activating enzyme (Gfa) from Paracoccus denitrificans detected and purified via two-dimensional proton exchange NMR spectroscopy. J. Biol. Chem. 2002, 277, 3069-3072. [CrossRef] [PubMed]

85. Hopkinson, R.J.; Barlow, P.S.; Schofield, C.J.; Claridge, T.D. Studies on the reaction of glutathione and formaldehyde using NMR. Org. Biomol. Chem. 2010, 8, 4915-4920. [CrossRef] [PubMed]

86. Sanghani, P.C.; Davis, W.I.; Zhai, L.; Robinson, H. Structure-function relationships in human glutathione-dependent formaldehyde dehydrogenase. Role of Glu-67 and Arg-368 in the catalytic mechanism. Biochemistry 2006, 45, 4819-4830. [CrossRef]

87. Gonzalez, C.F.; Proudfoot, M.; Brown, G.; Korniyenko, Y.; Mori, H.; Savchenko, A.V.; Yakunin, A.F. Molecular basis of formaldehyde detoxification. Characterization of two $S$-formylglutathione hydrolases from Escherichia coli, FrmB and YeiG. J. Biol. Chem. 2006, 281, 14514-14522. [CrossRef]

88. Salinas, A.E.; Wong, M.G. Glutathione S-transferases-a review. Curr. Med. Chem. 1999, 6, $279-309$.

89. Sheehan, D.; Meade, G.; Foley, V.M.; Dowd, C.A. Structure, function and evolution of glutathione transferases: Implications for classification of non-mammalian members of an ancient enzyme superfamily. Biochem. J. 2001, 360, 1-16. [CrossRef]

90. Oakley, A. Glutathione transferases: A structural perspective. Drug Metab. Rev. 2011, 43, 138-151. [CrossRef]

91. Mashiyama, S.T.; Malabanan, M.M.; Akiva, E.; Bhosle, R.; Branch, M.C.; Hillerich, B.; Jagessar, K.; Kim, J.; Patskovsky, Y.; Seidel, R.D.; et al. Large-scale determination of sequence, structure, and function relationships in cytosolic glutathione transferases across the biosphere. PLoS Biol. 2014, 12, e1001843. [CrossRef] [PubMed]

92. Meux, E.; Prosper, P.; Ngadin, A.; Didierjean, C.; Morel, M.; Dumarçay, S.; Lamant, T.; Jacquot, J.P.; Favier, F.; Gelhaye, E. Glutathione transferases of Phanerochaete chrysosporium: S-glutathionyl-p-hydroquinone reductase belongs to a new structural class. J. Biol. Chem. 2011, 286, 9162-9173. [CrossRef] [PubMed]

93. Oztetik, E.; Cakir, A. New food for an old mouth: New enzyme for an ancient archaea. Enzyme Microb. Technol. 2014, 55, 58-64. [CrossRef] [PubMed]

94. Di Matteo, A.; Federici, L.; Masulli, M.; Carletti, E.; Santorelli, D.; Cassidy, J.; Paradisi, F.; Di Ilio, C.; Allocati, N. Structural characterization of the Xi class glutathione transferase from the haloalkaliphilic archaeon Natrialba magadii. Front. Microbiol. 2019, 10, 9. [CrossRef] [PubMed]

95. Heinemann, J.; Hamerly, T.; Maaty, W.S.; Movahed, N.; Steffens, J.D.; Reeves, B.D.; Hilmer, J.K.; Therien, J.; Grieco, P.A.; Peters, J.W.; et al. Expanding the paradigm of thiol redox in the thermophilic root of life. Biochim. Biophys. Acta 2014, 1840, 80-85. [CrossRef]

96. Hillion, M.; Antelmann, H. Thiol-based redox switches in prokaryotes. Biol. Chem. 2015, 396, 415-444. [CrossRef]

97. Zheng, M.; Storz, G. Redox sensing by prokaryotic transcription factors. Biochem. Pharmacol. 2000, 59, 1-6. [CrossRef]

98. Georgiou, G. How to flip the (redox) switch. Cell 2002, 111, 607-610. [CrossRef]

99. Storz, G.; Tartaglia, L.A.; Ames, B.N. Transcriptional regulator of oxidative stress-inducible genes: Direct activation by oxidation. Science 1990, 248, 189-194. [CrossRef] 
100. Zheng, M.; Aslund, F.; Storz, G. Activation of the OxyR transcription factor by reversible disulfide bond formation. Science 1998, 279, 1718-1721. [CrossRef]

101. Lee, J.W.; Soonsanga, S.; Helmann, J.D. A complex thiolate switch regulates the Bacillus subtilis organic peroxide sensor OhrR. Proc. Natl. Acad. Sci. USA 2007, 104, 8743-8748. [CrossRef] [PubMed]

102. Fuangthong, M.; Atichartpongkul, S.; Mongkolsuk, S.; Helmann, J.D. OhrR is a repressor of $o h r A$, a key organic hydroperoxide resistance determinant in Bacillus subtilis. J. Bacteriol. 2001, 183, 4134-4141. [CrossRef] [PubMed]

103. Swem, L.R.; Kraft, B.J.; Swem, D.L.; Setterdahl, A.T.; Masuda, S.; Knaff, D.B.; Zaleski, J.M.; Bauer, C.E. Signal transduction by the global regulator RegB is mediated by a redox-active cysteine. EMBO J. 2003, 22, 4699-4708. [CrossRef] [PubMed]

104. Malik, B.; Su, W.W.; Wald, H.L.; Blumentals, I.I.; Kelly, R.M. Growth and gas production for hyperthermophilic archaebacterium, Pyrococcus furiosus. Biotechnol. Bioeng. 1989, 34, 1050-1057. [CrossRef]

105. Lipscomb, G.L.; Schut, G.J.; Scott, R.A.; Adams, M.W.W. SurR is a master regulator of the primary electron flow pathways in the order Thermococcales. Mol. Microbiol. 2017, 104, 869-881. [CrossRef]

106. Yang, H.; Lipscomb, G.L.; Keese, A.M.; Schut, G.J.; Thomm, M.; Adams, M.W.; Wang, B.C.; Scott, R.A. SurR regulates hydrogen production in Pyrococcus furiosus by a sulfur-dependent redox switch. Mol. Microbiol. 2010, 77, 1111-1122. [CrossRef]

107. Lipscomb, G.L.; Keese, A.M.; Cowart, D.M.; Schut, G.J.; Thomm, M.; Adams, M.W.; Scott, R.A. SurR: A transcriptional activator and repressor controlling hydrogen and elemental sulphur metabolism in Pyrococcus furiosus. Mol. Microbiol. 2009, 71, 332-349. [CrossRef]

108. Lim, J.K.; Jung, H.C.; Kang, S.G.; Lee, H.S. Redox regulation of SurR by protein disulfide oxidoreductase in Thermococcus onnurineus NA1. Extremophiles 2017, 21, 491-498. [CrossRef]

109. Isom, C.E.; Turner, J.L.; Lessner, D.J.; Karr, E.A. Redox-sensitive DNA binding by homodimeric Methanosarcina acetivorans MsvR is modulated by cysteine residues. BMC Microbiol. 2013, 13, 163. [CrossRef]

110. Karr, E.A. The methanogen-specific transcription factor MsvR regulates the fpaA-rlp-rub oxidative stress operon adjacent to msvR in Methanothermobacter thermautotrophicus. J. Bacteriol. 2010, 192, 5914-5922. [CrossRef]

111. Sheehan, R.; McCarver, A.C.; Isom, C.E.; Karr, E.A.; Lessner, D.J. The Methanosarcina acetivorans thioredoxin system activates DNA binding of the redox-sensitive transcriptional regulator MsvR. J. Ind. Microbiol. Biotechnol. 2015, 42, 965-969. [CrossRef] [PubMed]

112. Fiege, K.; Frankenberg-Dinkel, N. Thiol-based redox sensing in the methyltransferase associated sensor kinase RdmS in Methanosarcina acetivorans. Environ. Microbiol. 2019, 21, 1597-1610. [CrossRef] [PubMed]

113. delCardayre, S.B.; Stock, K.P.; Newton, G.L.; Fahey, R.C.; Davies, J.E. Coenzyme A disulfide reductase, the primary low molecular weight disulfide reductase from Staphylococcus aureus. Purification and characterization of the native enzyme. J. Biol. Chem. 1998, 273, 5744-5751. [CrossRef] [PubMed]

114. Eggers, C.H.; Caimano, M.J.; Malizia, R.A.; Kariu, T.; Cusack, B.; Desrosiers, D.C.; Hazlett, K.R.; Claiborne, A.; Pal, U.; Radolf, J.D. The coenzyme A disulphide reductase of Borrelia burgdorferi is important for rapid growth throughout the enzootic cycle and essential for infection of the mammalian host. Mol. Microbiol. 2011, 82, 679-697. [CrossRef]

115. Boylan, J.A.; Hummel, C.S.; Benoit, S.; Garcia-Lara, J.; Treglown-Downey, J.; Crane, E.J.; Gherardini, F.C. Borrelia burgdorferi bb0728 encodes a coenzyme A disulphide reductase whose function suggests a role in intracellular redox and the oxidative stress response. Mol. Microbiol. 2006, 59, 475-486. [CrossRef]

116. Hummel, C.S.; Lancaster, K.M.; Crane, E.J. Determination of coenzyme A levels in Pyrococcus furiosus and other Archaea: Implications for a general role for coenzyme A in thermophiles. FEMS Microbiol. Lett. 2005, 252, 229-234. [CrossRef]

117. Harris, D.R.; Ward, D.E.; Feasel, J.M.; Lancaster, K.M.; Murphy, R.D.; Mallet, T.C.; Crane, E.J. Discovery and characterization of a Coenzyme A disulfide reductase from Pyrococcus horikoshii. Implications for this disulfide metabolism of anaerobic hyperthermophiles. FEBS J. 2005, 272, 1189-1200. [CrossRef]

118. Wallen, J.R.; Paige, C.; Mallett, T.C.; Karplus, P.A.; Claiborne, A. Pyridine nucleotide complexes with Bacillus anthracis coenzyme A-disulfide reductase: A structural analysis of dual NAD $(\mathrm{P}) \mathrm{H}$ specificity. Biochemistry 2008, 47, 5182-5193. [CrossRef]

119. Bornemann, C.; Jardine, M.A.; Spies, H.S.; Steenkamp, D.J. Biosynthesis of mycothiol: Elucidation of the sequence of steps in Mycobacterium smegmatis. Biochem. J. 1997, 325 (Pt 3), 623-629. [CrossRef] 
120. Sakuda, S.; Zhou, Z.Y.; Yamada, Y. Structure of a novel disulfide of 2-(N-acetylcysteinyl)amido-2-deoxyalpha-D-glucopyranosyl-myo-inositol produced by Streptomyces sp. Biosci. Biotechnol. Biochem. 1994, 58, 1347-1348. [CrossRef]

121. Newton, G.L.; Unson, M.D.; Anderberg, S.J.; Aguilera, J.A.; Oh, N.N.; delCardayre, S.B.; Av-Gay, Y.; Fahey, R.C. Characterization of Mycobacterium smegmatis mutants defective in 1-d-myo-inosityl-2-amino2-deoxy-alpha-d-glucopyranoside and mycothiol biosynthesis. Biochem. Biophys. Res. Commun. 1999, 255, 239-244. [CrossRef] [PubMed]

122. Newton, G.L.; Koledin, T.; Gorovitz, B.; Rawat, M.; Fahey, R.C.; Av-Gay, Y. The glycosyltransferase gene encoding the enzyme catalyzing the first step of mycothiol biosynthesis (mshA). J. Bacteriol. 2003, 185, 3476-3479. [CrossRef] [PubMed]

123. Newton, G.L.; Av-Gay, Y.; Fahey, R.C. N-Acetyl-1-D-myo-inosityl-2-amino-2-deoxy-alpha-D-glucopyranoside deacetylase (MshB) is a key enzyme in mycothiol biosynthesis. J. Bacteriol. 2000, 182, 6958-6963. [CrossRef] [PubMed]

124. Rawat, M.; Newton, G.L.; Ko, M.; Martinez, G.J.; Fahey, R.C.; Av-Gay, Y. Mycothiol-deficient Mycobacterium smegmatis mutants are hypersensitive to alkylating agents, free radicals, and antibiotics. Antimicrob. Agents Chemother. 2002, 46, 3348-3355. [CrossRef] [PubMed]

125. Sareen, D.; Steffek, M.; Newton, G.L.; Fahey, R.C. ATP-dependent L-cysteine:1D-myo-inosityl 2-amino-2-deoxy-alpha-D-glucopyranoside ligase, mycothiol biosynthesis enzyme MshC, is related to class I cysteinyl-tRNA synthetases. Biochemistry 2002, 41, 6885-6890. [CrossRef] [PubMed]

126. Newton, G.L.; Ta, P.; Fahey, R.C. A mycothiol synthase mutant of Mycobacterium smegmatis produces novel thiols and has an altered thiol redox status. J. Bacteriol. 2005, 187, 7309-7316. [CrossRef] [PubMed]

127. Rawat, M.; Uppal, M.; Newton, G.; Steffek, M.; Fahey, R.C.; Av-Gay, Y. Targeted mutagenesis of the Mycobacterium smegmatis mca gene, encoding a mycothiol-dependent detoxification protein. J. Bacteriol. 2004, 186, 6050-6058. [CrossRef]

128. Steffek, M.; Newton, G.L.; Av-Gay, Y.; Fahey, R.C. Characterization of Mycobacterium tuberculosis mycothiol S-conjugate amidase. Biochemistry 2003, 42, 12067-12076. [CrossRef]

129. Patel, M.P.; Blanchard, J.S. Expression, purification, and characterization of Mycobacterium tuberculosis mycothione reductase. Biochemistry 1999, 38, 11827-11833. [CrossRef]

130. Newton, G.L.; Rawat, M.; La Clair, J.J.; Jothivasan, V.K.; Budiarto, T.; Hamilton, C.J.; Claiborne, A.; Helmann, J.D.; Fahey, R.C. Bacillithiol is an antioxidant thiol produced in Bacilli. Nat. Chem. Biol. 2009, 5 , 625-627. [CrossRef]

131. Upton, H.; Newton, G.L.; Gushiken, M.; Lo, K.; Holden, D.; Fahey, R.C.; Rawat, M. Characterization of BshA, bacillithiol glycosyltransferase from Staphylococcus aureus and Bacillus subtilis. FEBS Lett. 2012, 586, 1004-1008. [CrossRef] [PubMed]

132. Parsonage, D.; Newton, G.L.; Holder, R.C.; Wallace, B.D.; Paige, C.; Hamilton, C.J.; Dos Santos, P.C.; Redinbo, M.R.; Reid, S.D.; Claiborne, A. Characterization of the N-acetyl- $\alpha$-D-glucosaminyl l-malate synthase and deacetylase functions for bacillithiol biosynthesis in Bacillus anthracis. Biochemistry 2010, 49, 8398-8414. [CrossRef] [PubMed]

133. Gaballa, A.; Newton, G.L.; Antelmann, H.; Parsonage, D.; Upton, H.; Rawat, M.; Claiborne, A.; Fahey, R.C.; Helmann, J.D. Biosynthesis and functions of bacillithiol, a major low-molecular-weight thiol in Bacilli. Proc. Natl. Acad. Sci. USA 2010, 107, 6482-6486. [CrossRef] [PubMed]

134. Sharma, S.V.; Jothivasan, V.K.; Newton, G.L.; Upton, H.; Wakabayashi, J.I.; Kane, M.G.; Roberts, A.A.; Rawat, M.; La Clair, J.J.; Hamilton, C.J. Chemical and chemoenzymatic syntheses of bacillithiol: A unique low-molecular-weight thiol amongst low G + C Gram-positive bacteria. Angew. Chem. Int. Ed Engl. 2011, 50, 7101-7104. [CrossRef] [PubMed]

135. Zaremba-Niedzwiedzka, K.; Caceres, E.F.; Saw, J.H.; Bäckström, D.; Juzokaite, L.; Vancaester, E.; Seitz, K.W.; Anantharaman, K.; Starnawski, P.; Kjeldsen, K.U.; et al. Asgard archaea illuminate the origin of eukaryotic cellular complexity. Nature 2017, 541, 353-358. [CrossRef] [PubMed]

136. Mikheyeva, I.V.; Thomas, J.M.; Kolar, S.L.; Corvaglia, A.R.; Gaïa, N.; Leo, S.; Francois, P.; Liu, G.Y.; Rawat, M.; Cheung, A.L. YpdA, a putative bacillithiol disulfide reductase, contributes to cellular redox homeostasis and virulence in Staphylococcus aureus. Mol. Microbiol. 2019, 111, 1039-1056. [CrossRef] 
137. Linzner, N.; Loi, V.V.; Fritsch, V.N.; Tung, Q.N.; Stenzel, S.; Wirtz, M.; Hell, R.; Hamilton, C.J.; Tedin, K.; Fulde, M.; et al. Staphylococcus aureus uses the bacilliredoxin (BrxAB)/bacillithiol disulfide reductase (YpdA) redox pathway to defend against oxidative stress under infections. Front. Microbiol. 2019, 10, 1355. [CrossRef]

138. Imachi, H.; Nobu, M.K.; Nakahara, N.; Morono, Y.; Ogawara, M.; Takaki, Y.; Takano, Y.; Uematsu, K.; Ikuta, T.; Ito, M.; et al. Isolation of an archaeon at the prokaryote-eukaryote interface. Nature 2020, 577, 519-525. [CrossRef]

139. Cheah, I.K.; Halliwell, B. Ergothioneine; antioxidant potential, physiological function and role in disease. Biochim. Biophys. Acta 2012, 1822, 784-793. [CrossRef]

140. Pfeiffer, C.; Bauer, T.; Surek, B.; Schömig, E.; Gründemann, D. Cyanobacteria produce high levels of ergothioneine. Food Chem. 2011, 129, 1766-1769. [CrossRef]

141. Jones, G.W.; Doyle, S.; Fitzpatrick, D.A. The evolutionary history of the genes involved in the biosynthesis of the antioxidant ergothioneine. Gene 2014, 549, 161-170. [CrossRef] [PubMed]

142. Leisinger, F.; Burn, R.; Meury, M.; Lukat, P.; Seebeck, F.P. Structural and mechanistic basis for anaerobic ergothioneine biosynthesis. J. Am. Chem. Soc. 2019, 141, 6906-6914. [CrossRef] [PubMed]

143. Burn, R.; Misson, L.; Meury, M.; Seebeck, F.P. Anaerobic origin of ergothioneine. Angew. Chem. Int. Ed. Engl. 2017, 56, 12508-12511. [CrossRef] [PubMed]

(C) 2020 by the authors. Licensee MDPI, Basel, Switzerland. This article is an open access article distributed under the terms and conditions of the Creative Commons Attribution (CC BY) license (http://creativecommons.org/licenses/by/4.0/). 